\title{
The Sheffield experiment: the effects of centralising accident and emergency services in a large urban setting
}

\author{
A N Simpson, J Wardrope, D Burke
}

\begin{abstract}
Objectives-To assess the effects of centralisation of accident and emergency $(A \& E)$ services in a large urban setting. The end points were the quality of patient care judged by time to see a doctor or nurse practitioner, time to admission and the cost of the $A \& E$ service as a whole.

Methods-Sheffield is a large industrial city with a population of 471000 . In 1994 Sheffield health authority took a decision to centralise a number of services including the $A \& E$ services. This study presents data collected over a three year period before, during and after the centralisation of adult $A \& E$ services from two sites to one site and the centralisation of children's A\&E services to a separate site. A minor injury unit was also established along with an emergency admissions unit. The study used information from the $A \& E$ departments' computer system and routinely available financial data.
\end{abstract}

Results-There has been a small decrease in the number of new patient attendances using the Sheffield A\&E system. Most patients go to the correct department. The numbers of acute admissions through the adult A\&E have doubled. Measures of process efficiency show some improvement in times to admission. There has been measurable deterioration in the time to be seen for minor injuries in the $A \& E$ departments. This is partly offset by the very good waiting time to be seen in the minor injuries unit. The costs of providing the service within Sheffield have increased.

Conclusion-Centralisation of A\&E services in Sheffield has led to concentration of the most ill patients in a single adult department and separate paediatric $A \& E$ department. Despite a greatly increased number of admissions at the adult site this change has not resulted in increased waiting times for admission because of the transfer of adequate beds to support the changes. There has however been a dete- rioration in the time to see a clinician, especially in the $A \& E$ departments. The waiting times at the minor injury unit are very short.

(Emerg Med f 2001;18:193-197)

Keywords: accident and emergency services; service re-organisation; costs; quality indicators

Before 1997, Sheffield had three accident and emergency (A\&E) departments within three miles of each other. Several recent reports have indicated that where departments are sited adjacent to each other there is a good argument that services should be amalgamated onto one site. $^{1-5}$ There are increasing pressures to provide more senior cover in departments so that inexperienced junior doctors are not left alone to deal with seriously injured or sick patients, this cover is expensive and may only be viable if it is not spread over several sites. ${ }^{45}$

In September 1994 Sheffield Health Authority and the provider trusts agreed to a major reorganisation of acute services including centralisation of orthopaedic, paediatric, and vascular services, and of obstetrics and gynaecology, which will centralise in $2001 .^{6} \mathrm{~A} \& \mathrm{E}$ reorganisation was to lead to the creation of single, separate adult department (Northern General Hospital-NGH) and children's services (Sheffield Children's Hospital-SCH). In addition a minor injuries unit (MIU) and an Emergency Admissions Unit (EAU) at the Royal Hallamshire Hospital (RHH) were planned. This EAU was mainly for GP referrals, but ambulance crews would be able to take patients with a cardiac arrest or possible myocardial infarction to this facility. The service configurations for the three hospitals during this period are shown in table 1 .

The major opportunities for the A\&E service included the ability to centralise scarce resource of experienced $A \& E$ staff to deal with the sickest patients, to help cope with the increasing demands of manpower planning, junior doctors' hours of work and supervision for those in training. In addition it was hoped
Hospital, Herries

Road, Sheffield

S5 7 AU, UK

J Wardrope

Sheffield Children's Hospital

A N Simpson

D Burke

Correspondence to: Mr Wardrope

(jimwardrope@hotmail.com)

Accepted for publication 12 June 2000
Table 1 Configuration and opening times of $A \mathcal{E} E$ E services in Sheffield. Before, during and after the changes

\begin{tabular}{llll}
\hline AEE department & $1995 / 96$ & $1996 / 97$ & $1997 / 98$ \\
\hline Northern General Hospital & Open 3 nights & 24 hours & 24 hours \\
& All ages & All ages & Adults \\
Royal Hallamshire Hospital & Open 4 nights & $0800-2000$ & MIU 0800-2000 \\
& Adults & Adults & EAU cardiac arrest and possible MI patients \\
& & Adults \\
Sheffield Children's Hospital & 24 hours & 24 hours & 24 hours \\
& Children & Children & Children \\
\hline
\end{tabular}


Table 2 Annual new patient attendances for each site before, during and after the changes to $A \mathcal{E} E$ services

\begin{tabular}{llll}
\hline Department & $1995 / 96$ & $1996 / 97$ & $1997 / 98$ \\
\hline Northern General Hospital & 47048 & 61662 & 74403 \\
Royal Hallamshire Hospital & 50893 & 37427 & - \\
Emergency Admissions Unit & - & - & 474 \\
Minor Injuries Unit & - & - & 13619 \\
Sheffield Children's Hospital & 27582 & 124963 & 32796 \\
Total & 125523 & 120818 \\
\hline
\end{tabular}

that the changes in critical mass that would allow expansion of some clinical services, teaching and research.

The aim of the study was to examine the effects of these changes on the processes of care within the whole A\&E system by comparing waiting times for all patients. Times to admission were used as a measure of the process efficiency of the whole system in caring for the most ill patients. A further aim was to compare overall costs of the system. This information was to provide an effective audit of the changes for the health authority and trusts but hopefully other areas considering such change might learn from this experience.

The "null hypothesis" was that there would be no change in the measures of process efficiency and no change in the overall costs of the system.

\section{Method}

Following the decision to centralise services, a project group was established to examine the effects on patient care before, during and after these changes. Markers were chosen to look at the various aspects of care including the management of acute myocardial infarction ${ }^{78}$ and chest pain (as a marker of care of serious illness), use of established trauma audit methods (serious injury). Two major studies were set up to evaluate the effects on minor injuries, specifically evaluating the efficacy of emergency nurse practitioners (ENPs), ${ }^{9}$ and the cost efficiency of the new minor injuries unit (in preparation). It was also planned to use routine volume, quality and cost data to give an overview of the effects of change. Steps were taken to harmonise the clinical coding systems of the $\mathrm{A} \& \mathrm{E}$ departments and to try and improve data quality and data collection rates. It is the analysis of these "routine" data that is presented in this paper.

All three hospitals involved in the changes collected arrival time, time to be seen by either a doctor or ENP and time to admission to a hospital bed. Data were analysed for three single year periods $95 / 96,96 / 97$ and $97 / 98$. Waiting time to see a doctor is defined as the time seen by a doctor or ENP minus the booking in time. The department time for admitted patients, for the purposes of this study, is the time the patient arrived in a hospital bed minus the booking in time. It should be noted that this is not the "trolley time" but a better reflection of time spent in $A \& E$ and a superior representation of use of $\mathrm{A} \& \mathrm{E}$ resources. ${ }^{10}$ Anomalies such as incorrect use of the 24 hour clock were corrected.

Further information was obtained from the surrounding district general hospitals of
Rotherham and Chesterfield who might experience an increase in workload. Information on the EAU attendances was produced by the RHH.

The revenue costs illustrated are based on information provided by the accounting departments of the NGH and $\mathrm{SCH}$. The costs exclude radiographic costs as these are not stated on the budget information at the NGH. They have been adjusted for inflation based on the following; pay inflation for medical staff from $1995 / 96$ to $1997 / 98$ saw a rise of $8.55 \%$, for nursing staff $7.29 \%$ and for non-pay $4.04 \%$.

The data were stored on the Access database and analysed using Excel. We used $\chi^{2}$ tests to assess the statistical significance of any differences between the numbers within the waiting time and time to admission standards compared with numbers within these standards before the change.

\section{Results}

TOTAL ATTENDANCE

The total number of new patient attendances (excluding planned returns) to the $A \& E$ service in Sheffield for the three year period is shown in table 2 . There has been a reduction in use of A\&E services in Sheffield of 4705 (3.75\%) new $A \& E$ attendances. A further 474 were taken directly to the EAU by the ambulance service without prior GP consultation. Rotherham District General Hospital saw 807 more new attendances from Sheffield residents and Chesterfield Royal Infirmary 581 more new attendances (total numbers of new patients per annum for these departments, 54000 and 49000 respectively). However, even when allowing for these other possible sources of $A \& E$ care there has been a reduction of 2833 new attendances from 1995/96 to $1997 / 98(2.26 \%)$.

Occasionally patients referred themselves to the wrong hospital. Of those arriving at the MIU, 39 had chest pain or a cardiac condition, the remaining 21 having conditions including asthma, renal colic, collapse and overdose. These patients were referred to the EAU after initial assessment by the ENPs (all trained in advanced life support). In addition 35 patients with eye problems (excluding foreign bodies) were referred to ophthalmology. Approximately 40 children per month are being seen in triage at the NGH. The majority of these children have minor injuries or illnesses and are referred to the Children's Hospital. For those requiring resuscitation the majority of senior and middle grade staff are Advanced Paediatric Life Support providers or instructors and have had experience in paediatric A\&E. There is also a paediatric registrar 24 hours per day covering the special care baby unit who will attend if required.

PROCESS EFFICIENCY

Time to be seen by a clinician

At the NGH and $\mathrm{RHH}$, before the changes, $74435(76 \%)$ of new patients were being seen within one hour of arrival. After the changes there had been a reduction to 62496 (71\%) 
Table 3 Waiting time to see a clinician for the NGH/RHH service 95/96, 96/97 and for the NGH/MIU service $97 / 98$

\begin{tabular}{llllll}
\hline & $<1$ hour & $1-2$ hours & 2-3 hours & $>3$ hours & Not known \\
\hline $1995-96$ & $74435(76 \%)$ & $17139(17.5 \%)$ & $3624(3.7 \%)$ & $1175(1.2 \%)$ & $1567(1.6 \%)$ \\
$1996-97$ & $73326(74 \%)$ & $17638(17.8 \%)$ & $4558(4.6 \%)$ & $1387(1.4 \%)$ & $2180(2.2 \%)$ \\
$1997-98$ & $62496(71 \%)$ & $17428(19.8 \%)$ & $3873(4.4 \%)$ & $1144(1.3 \%)$ & $3081(3.5 \%)$ \\
\hline
\end{tabular}

Table 4 Department times for admitted patients, NGH service before, during and after the change

\begin{tabular}{llllll}
\hline & 0-2 hours & 2-4 hours & 4-8 hours & $>8$ hours & Not known \\
\hline 1995-96 (total 8992) & $4136(46 \%)$ & $2788(31 \%)$ & $989(11 \%)$ & $180(2 \%)$ & $899(10 \%)$ \\
$1996-97$ (total 13 116) & $6427(49 \%)$ & $4984(38 \%)$ & $1443(11 \%)$ & $79(0.6 \%)$ & $184(1.4 \%)$ \\
$1997-98($ total 18 270) & $8952(49 \%)$ & $7125(39 \%)$ & $2010(11 \%)$ & $55(0.3 \%)$ & $128(0.7 \%)$ \\
\hline
\end{tabular}

seen within one hour. However, these aggregate figures disguise a more marked deterioration at the NGH site as the minor injuries unit is seeing 13347 (98\%) of its patients within one hour, while the NGH saw only 49105 $(66 \%)$ within the hour (table 3). In the Children's Hospital 24824 (90\% of the total) were seen within one hour before the change but after the change the proportion of children seen within one hour also fell to 26237 (80\% of the total).

This increase in time to see a clinician was significant with proportionately less patients being seen within one hour throughout the whole system than before the changes $\left(\chi^{2}=\right.$ $1340,1$ degree of freedom, $p<0.001)$, or for those using the adult service where the times are known $\left(\chi^{2}=610,3\right.$ degrees of freedom, $\mathrm{p}<0.001)$.

Time to admit to a hospital bed

Over the three year period combined total admissions through the $\mathrm{A} \& \mathrm{E}$ department of the $\mathrm{RHH}$ and $\mathrm{NGH}$ rose by 500 cases. However, the number of admissions through the A\&E department at NGH doubled from 8500 to 18000 . The time to admit to a hospital bed from booking at $\mathrm{A} \& \mathrm{E}$ reception was used as a measure of the functioning of the system as a whole with regard to emergency patients.

There has been a slight improvement in the number of patients managing to get to a hospital bed within two hours of arrival. This should be tempered by the fact that among the $1995 / 96$ figures $10 \%$ are in the category "unknown", and it is possible that all of these patients were admitted within one hour. However, it is clear that despite a rise in the number of admissions through the A\&E department at the NGH from 8992 in $1995 / 96$ to 18270 in $1997 / 98$ there has been an improvement in the waiting time for a hospital bed (table 4, fig 1). The waiting time profile at the $\mathrm{RHH}$ before the changes was not as good as at the NGH and therefore the change, if measured over the whole system would be greater. Comparing data where the waiting time is known, there was a significant reduction in waiting times for admission at the NGH before and after the changes (for all categories $\chi^{2}=599,3$ degrees of freedom, $\mathrm{p}<0.001$ or for patients admitted in less or more than four hours $\chi^{2}=186,1$ degree of freedom $\mathrm{p}>0.001$ ).

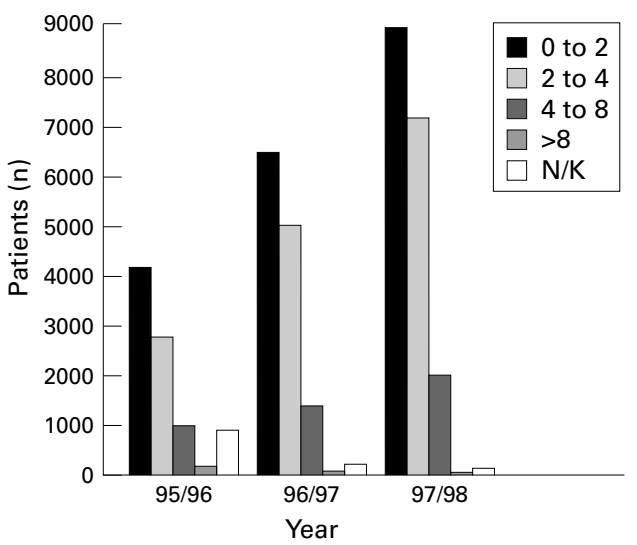

Figure 1 Graph showing department times of admitted patients, NGH service before, during and after the change.

Table 5 Cost in $\mathcal{E}$ of the AE E services before and after the changes, adjusted for inflation

\begin{tabular}{lll}
\hline & $1995 / 96$ & $1997 / 98$ \\
\hline NGH & 1405065 & 2700958 \\
RHH & $173304 ?$ & 0 \\
MIU & 0 & 281615 \\
SCH & 843593 & 111766 \\
Total & 3981702 & 4099939 \\
\hline
\end{tabular}

Admission figures for the NGH have been independently audited recently by District Audit using Audit Commission methods. That report produced quality results similar to our findings and stated NGH has the shortest waiting times for admitted patients of any teaching hospital trust outside London. ${ }^{11}$

CRUDE REVENUE COSTS

Total revenue costs of the $\mathrm{A} \& \mathrm{E}$ services have risen from $£ 3981702$ to $£ 4099939$ (total change $£ 118437,2.9 \%)$. These costs have been adjusted for inflation and reflect revenue expenditure. They do not include capital expenditure generated by building work or equipment costs as a result of the reorganisation. They do not assess effects on the costs of other services that were reorganised at the same time. The costs per case have risen from $£ 32.04$ per case at the $\mathrm{NGH} / \mathrm{RHH}$ to $£ 33.88$ for the NGH/MIU facilities. This might be expected because of the more acute case mix at the main adult site and some inefficiency with the fixed costs of staffing the MIU site. Non-pay costs increased but nursing costs decreased by $£ 100000$, even allowing for the 8.5 WTE nurses and two reception staff at the MIU site. The costs also rose at the $\mathrm{SCH}$ from $£ 30.60$ to $£ 34.07$ but with no obvious change in case mix. The main cost was a very significant increase in nursing levels (14.5 to 22.5 WTE) and a slight increase in medical staff (2 WTE.) There was also a very large rise in non-pay costs (table 5).

\section{Discussion}

Centralisation of acute services was one of the main themes of a number of reports during the 1990s. The main drivers have been the increasing standards expected in providing cover for acute rotas with ever more experienced and specialised doctors, the need to 
provide "critical mass" for certain services, and the need to provide junior staff with more supervision and training while cutting the number of hours that they work. These factors operate not only for A\&E but also for other major acute specialties. It was the drive to centralise services such as paediatrics that made it inevitable that there would be changes to $\mathrm{A} \& \mathrm{E}$ services in Sheffield.

There is little published evidence about the effects on patient care of such processes and this was the main aim of the study. However, it is important to review some of the benefits of centralisation to the $A \& E$ service. The $A \& E$ departments have much better levels of senior doctor cover with consultant shifts in the evenings and middle grade cover from 0800 to 2400 (and to 0300 on Friday and Saturday nights). This has allowed improvements in the key clinical quality measures such as the time to thrombolysis ${ }^{78}$ and the level of senior staff attending trauma resuscitations. New services have been developed such as a chest pain assessment unit, ${ }^{12}$ an Assessment and Integrated Care Scheme (social care) and an out of hours psychiatric intervention team. Some of these might have happened in the absence of centralisation but having one main adult department has made them much more effective.

The research output of the A\&E service both at the $\mathrm{NGH}$ and $\mathrm{SCH}$ has greatly improved in both quality and quantity and it is unlikely that this would have happened without centralisation. The consultants have had increased time to effectively establish a number of research programmes rather than debate and defend service changes.

Teaching has always been a major feature of the Sheffield A\&E services but this has been strengthened, especially in nurse education and training and in specialist registrar training.

Children are now all seen in a dedicated children's A\&E department with the full back up of specialised tertiary care children's facilities that meet the criteria set for staffing and quality. ${ }^{513}$ However, there are problems in divorcing the children's service from the adult service. Training is more complex and SHOs at the NGH miss this experience. There are inefficiencies of fully staffing the children's service at night when there are few attendances, a time when the adult service is under increasing pressure. Occasionally families are involved in a single accident. Most of the time however, there is no need to split the family as it is not often that both the adults and children have injuries that require immediate management.

One of the major concerns in such a reorganisation is the ability of a hospital to support the $\mathrm{A} \& \mathrm{E}$ department. One of the keys to success of the changes was the transfer of 200 extra beds to the NGH to help cope with the extra general medical and orthopaedic workload. It is this planning, along with detailed cooperation between units over emergency admissions, that made it possible to improve on the quality indicator of time to admission. However, the large increase in admissions has led to problems in the sheer volume and rate of presentation of ill patients to the general medical teams. Even before the changes general medicine at the $\mathrm{NGH}$ was very well organised, with an acute admissions ward, two or three teams consisting of three consultants, their staff being available for each "take" and integration of Medicine for the Elderly with acute general medicine. However, even with an increase of staff to cope with the extra workload, the greatest strain of the change has fallen on acute general medicine. The work intensity for junior doctors in acute medicine has led to the introduction of partial shift rotas and may lead to a full shift system.

At times of peak demand on general medicine there may be an impact on elective surgery as beds are very actively managed to provide enough capacity for the emergency workload. This can obviously have effects on waiting lists and performance against elective targets. Such effects have been kept to a minimum by diverting general practice emergency referrals to the $\mathrm{RHH}$ to balance any major demands on the NGH from A\&E admissions. The most important factor in any centralisation of $\mathrm{A} \& \mathrm{E}$ services is the adequate provision of inpatient services. Failure to do so will lead to major problems with the quality of service, both for emergency patients and for the elective workload of the hospital.

While the A\&E quality standards for time to admission have improved, the time to see a clinician for all patients has deteriorated. This is despite excellent figures at the MIU with $98 \%$ of patients seen within one hour. The philosophy of always giving priority to higher triage categories may work within small and medium sized departments but given the concentration of ill patients at the NGH, it has become necessary to change working practice to provide a more dedicated service for the less seriously ill and injured. The major effect brought about by the change in case mix at the NGH site was not appreciated during the planning stages. The loss of children, most of whom have relatively minor problems, and with many of the minor injuries being seen and treated at the MIU, the $\mathrm{NGH}$ now has a very acute case mix. Over $40 \%$ of patients arrive by 999 ambulance and almost $25 \%$ of all new patients are admitted. Medical staffing was calculated using formulas based on "average case mix" and nursing staffing on the experience of our departments before the changes.

The MIU has an inherent cost inefficiency in providing a separate (although jointly managed) service. It has excess capacity as shown by the very short times to see a clinician but these issues are currently being tackled. It does however provide easy local access to the population on the side of the city without an adult A\&E department.

The cost of the service has increased overall. The revenue cost per case for the NGH/MIU service has increased by $5.4 \%$ when compared with the NGH/RHH service before the changes. Case mix is very different with large numbers of acutely ill patients needing admission. This might explain some of the non-pay cost increases. It is also clear that the costs of 
the service would have had to increase even if there had been no change. For example the levels of senior cover for the departments fell far short of recommended levels and these deficiencies would have to have been resolved.

It is obviously cheaper to provide increased senior cover at one site rather than two sites. The service does cost more but there has been an increase in the number and quality of "outputs" in terms of senior cover, levels of service provision, teaching and research. Similarly at the SCH the cost per case has risen. Part of this increase was to rectify very low nurse staffing levels as well as to provide more senior cover. There has also been an increase in the teaching and research output at $\mathrm{SCH}$.

The centralisation of the A\&E service in Sheffield was only one part of a large jigsaw of service reorganisation. Most of the parts of that jigsaw have fallen into place but there still remain problems. The loss of obstetrics and gynaecology from the NGH site in 2001, along with paediatric cover, will increase the problems of dealing with any children that do attend the NGH. The pressures on acute general medicine are predicted to increase. The neurosurgical services based at the $\mathrm{RHH}$ remain divorced from all of the other main adult trauma specialties leaving a gap in tertiary care for trauma. Sheffield still does not have a perfect fit of services.

Has it all been worth it? From a professional A\&E perspective it has been a great success. For the seriously ill and injured patient attending the NGH there is an improved service, quicker thrombolysis, more senior cover in the resuscitation room and more speedy access to a hospital bed. For the patient with minor injuries attending the RHH there is an excellent and speedy service. However, the patient with a minor illness or minor injury attending the $\mathrm{NGH}$ faces increased waiting times, although they are more likely to be seen by an experienced doctor than before. The acute medical teams at the NGH are very stretched. A child attending the SCH is treated in a dedicated children's facility with the full back up of a major paediatric tertiary referral centre. The purchasers might be disappointed by the crude cost figures but they have been spared future costs that would have been required to meet deficiencies in senior cover and in nursing at the SCH. The results of the Sheffield experiment may not be completely transferable to other areas but we believe that many of the underlying principles for managing such changes are very relevant to any emergency care system.

We would like to thank, Mr RC Bailey, Chesterfield Royal Infirmary, Mr F L P Heyes, Rotherham District General Hospital, Mr D G Ferguson, Royal Hallamshire Hospital, for providing data, and Mr Chris Harrison for accounts advice. We would also like to express our thanks to the reviewers of this paper for their extremely helpful and constructive comments.

\section{Contributors}

AS wrote the paper, carried out some of the analysis, collected data from EAU/SCH/Chesterfield/Rotherham, DB provided and analysed the data from SCH and helped to write the paper. and analysed the data from $\mathrm{SCH}$ and helped to write the paper. JW designed the study, provided data and analysis from NGH Funding: A Simpson received funding and support for a secondment to Public Health Medicine.

Conflicts of interest: J Wardrope was the lead clinician during the planning and implementation phases of the changes to $\mathrm{A} \& \mathrm{E}$ in Sheffield. $\mathrm{He}$ is one of the editors of EMF but had no part in the editorial decision regarding publication of the article.

1 British Orthopaedic Association. The care of severely injured patients in the United Kingdom: an urgent need 1997. London: British Orthopaedic Association, 1997.

2 Working party on the management of patients with major injuries. Report of the working party on the management of patients with major injuries. London: Royal College of Surgeons of England, 1988 .

3 Working party on the provision of surgical services. The provision of emergency surgical services: an organisational framework. London: Royal College of Surgeons of England, 1997.

4 British Association for Accident and Emergency Medicine . The way ahead. London: BAEM, 1998.

5 The Audit Commission. By accident or design: improving $A \mathcal{E} E$ services in England and Wales. London: The Audit Commission, 1996

6 Sheffield Health Authority and Sheffield Family Health Services Authority. Purchasing for Health 1994-2000: A purchasing strategy for health in Sheffield for $1994 / 95$ and beyond. Sheffield: SHA \& SFHSA, 1994.

7 Edhouse JA, Wardrope J, Morris FP. Paramedic direct admission of heart attack patients to coronary care. Lancet 1998;352:2020.

8 Edhouse JA, Sakr M, Wardrope J, et al. Thrombolysis in acute myocardial infarction. The safety and efficiency of treatment in the accident and emergency department. $\mathcal{F}$ Accid Emerg Med 1999;16:325-30.

9 Sakr M, Angus J, Perrin J, et al. Care of minor injuries by emergency nurse practitioners or junior doctors: a emergency nurse practitioners or junio

10 The Audit Commission. Accident and emergency services follow up: progress against indicators from by accident or design. London: The Audit Commission, 1998

11 District Audit. Review of accident and emergency services Northern General Hospital NHS Trust Audit 1997/1998. Sheffield: District Audit, 1999.

2 Goodacre SW, Morris FP, Angelini K, et al. A descriptive study of a chest pain observation unit in a UK hospital. $\mathcal{f}$ Accid Emerg Med 2000;17:58

13 The Audit Commission. Children first: a study of hospital services. London: The Audit Commission,1993. 